\title{
ACERCA DE BOIS SUSTENTÁVEIS: REFLEXÕES SOBRE A AMBIENTALIZAÇÃO DA CADEIA PRODUTIVA DA CARNE
}

ABOUT SUSTAINABLE OXEN: REFLECTIONS ON THE ENVIRONMENTALIZATION OF THE MEAT PRODUCTION CHAIN

\section{Graciela Froehlich}

Pesquisadora colaboradora plena junto ao Programa de Pós-graduação em Antropologia Social da Universidade de Brasília (PPGAS/DAN/UnB). 


\section{RESUMO}

Este artigo escrutina algumas das estratégias de ambientalização utilizadas pela cadeia produtiva da carne no Brasil. Por ambientalização entende-se o processo de adoção por parte de diversos grupos - movimentos sociais, empresas e o próprio Estado - de discursos e/ou práticas que tematizam a questão ambiental (LEITE LOPES, 2006; ACSELRAD, 2010). Em um primeiro momento apresento algumas das controvérsias na atividade pecuária, sobretudo bovina, no que diz respeito aos seus impactos ambientais e sociais. Em seguida, procuro refletir sobre as certificações socioambientais - que almejam atestar a compatibilidade dos métodos empregados na produção de carne com os princípios de sustentabilidade - como estratégias de ambientalização da cadeia produtiva da carne.

PALAVRAS-CHAVE: ambientalização; pecuária bovina; carne; sustentabilidade.

\section{ABSTRACT}

This article examines some of the environmentalization strategies used by the meat production chain in Brazil. Environmentalization can be set as the process of adoption by various groups - social movements, companies and the state itself - of discourses and / or practices that address the environmental issue (LEITE LOPES, 2006; ACSELRAD, 20I0). At first, I present some of the controversies in livestock activity, especially cattle ranching, regarding their environmental and social impacts. Next, I try to think on the social and environmental certifications - which aim to attest the compatibility of methods used in meat production with the sustainability principles - as strategies for the environmentalization of the meat production chain.

KEYWORDS: environmentalization; cattle ranching; meat; sustainability. 
“Nossos 'superporcos' não serão apenas grandes e lindos, eles deixarão um impacto mínimo no ambiente, consumirão menos alimento e produzirão menos excrementos. E, o mais importante, eles serão gostosos pra caramba!"

(OKJA, 2OI7)

Nancy Mirando, CEO da Mirando Corporation, o empreendimento agroindustrial do filme Okja (20I7), assim caracteriza os animais que sua companhia produziu e cujas fisionomia, características e hábitos estavam guardados do grande público como um segredo empresarial. $\mathrm{O}$ "superporco" é uma nova raça suína, fruto de décadas de pesquisa científica. Apresenta formas avantajadas e crescimento acelerado, características reputadas como capazes de solucionar a escassez de alimentos e a fome dos humanos em uma Terra ameaçada pelas mudanças climáticas. As transformações de Okja evocam também os superporcos descritos por Margaret Atwood em Oryx e Crake (2004), criados pela OrganInc a fim de produzir múltiplos órgãos - rins, fígados e pulmões - para transplantes em seres humanos adoecidos pelas condições adversas de uma Terra arrasada.

A narrativa de Okja, filme lançado pela plataforma de streaming Netflix em maio de 20I7, nos é assustadoramente familiar, senão pela forma corporal do superporco, mas pelo marketing com o qual a empresa o apresenta. Porcos - e outros animais classificados como de produção ${ }^{1}$ - devem ser sustentáveis ambientalmente, criados de forma responsável e ter seu bem-estar respeitado. Essa tríade, além de tudo, os torna "gostosos pra caramba", como Nancy Mirando descreve a carne desses animais.

A Terra arrasada retratada nas obras de ficção científica está bem documentada nos estudos sobre o Antropoceno. Nessa nova era geológica (o Antropoceno), as intervenções humanas, do uso de combustíveis fósseis à agricultura em escala industrial, podem levar a um estado de danos irreversíveis das condições de vida no planeta (ROCKSTRÖM et al., 2009). O termo foi proposto pela primeira vez pelo químico atmosférico Paul J. Crutzen em uma pequena publicação em parceria com o especialista em ciência marinha Eugene F. Stoermer, The Anthropocene, publicado no boletim informativo do International Geosphere-Biosphere Programme (IGBP) (CRUTZEN; STOERMER, 2000).

O marco temporal, embora esteja ainda em discussão, tende a assinalar que o início dessa nova era geológica estaria situado no século XVIII, em função do advento da Revolução Industrial e do aumento nas concentrações de gás metano e dióxido de carbono na atmosfera (CRUTZEN, 2002). A partir desse momento, cresce em rapidez e intensidade a pressão humana sobre o Sistema Terra, ${ }^{2}$ através da construção de barragens, da transposição do leito dos rios, da

\footnotetext{
${ }^{1}$ Os animais de produção são aqueles criados para fins alimentícios em sistemas intensivos.

${ }^{2}$ Segundo o International Geosphere-Biosphere Programme (IGBP), o conceito de Sistema Terra refere-se à interação entre processos químicos, físicos e biológicos terrestres. É formado pelo solo, pela água, pela atmosfera e pelos polos; e inclui ciclos como os da água, do $D \& D[$ n.17| $2019.2 \mid$ pp. 9-24]
} 
exploração humana de quase 50\% da superfície do planeta, do desmatamento das florestas tropicais, da fixação de nitrogênio no solo pela agricultura, do uso de combustíveis fósseis e do uso indiscriminado de água potável (CRUTZEN, 2002).

A pecuária industrial insere-se nesse contexto como mais um agente a intensificar a crise climática e ambiental. A criação em larga escala de animais para servirem de alimento aos humanos - bois, porcos e galinhas - em nenhum outro momento histórico atingiu níveis tão elevados: em 20I2, mais de 70 bilhões de animais foram criados em todo o mundo para o consumo humano(FAOSTAT, 2OI3). No Brasil, destaca-se a pecuária bovina como diretamente relacionada ao desmatamento dos biomas Cerrado e Amazônia, contribuindo de maneira decisiva na emissão de dióxido de carbono e na perda ou redução da biodiversidade.

Esse cenário tem impactos no mercado de carnes, cujos agentes buscam, de maneira crescente, transmitir uma mensagem positiva quanto aos métodos empregados em seu processo produtivo. Ao acessarmos as páginas na internet de grandes empresas do setor de processamento, a exemplo da JBS, da Marfrig e do Tyson Group, encontraremos em cada uma delas uma aba denominada "sustentabilidade", na qual são apresentados os princípios, as pesquisas e as iniciativas gestadas em cada um dos empreendimentos. Segurança alimentar e nutricional, respeito aos trabalhadores, aos animais e ao ambiente, bem como práticas "razoáveis" de gerenciamento são alguns dos princípios abarcados pelo conceito de sustentabilidade utilizado por esses agentes. Lembram-nos, assim, da campanha de marketing da Mirando Corporation mencionada antes.

Se por um lado as grandes indústrias frigoríficas têm buscado contornar as acusações de agressão ao ambiente, também os pecuaristas se veem questionados quanto à possibilidade de criar animais e a partir deles produzir carne sem prejuízo dos "recursos naturais". As respostas a essa questão oscilam entre um grupo que nega a crise ambiental e, portanto, não vê motivos para se alterar os sistemas de produção; e outro, que sustenta a realidade das mudanças climáticas e defende alterações pontuais que preservem as atividades produtivas relacionadas à criação de animais para sua transformação em alimento. Estratégias de mitigação dos danos ambientais resultantes da atividade pecuária têm sido desenvolvidas em todo o mundo, e uma delas consiste em reconhecer, por meio de selos e certificações de origem, as ações de sustentabilidade de propriedades rurais dedicadas a atividades agropecuárias.

A seguir, aprofundo as reflexões sobre as controvérsias engendradas pela produção de carne, destacando, em um primeiro momento, as críticas direcionadas a esta indústria para, em seguida, examinar as certificações socioambientais como estratégia de ambientalização da indústria da carne. 


\section{Controvérsias da pecuária}

O Brasil detém o segundo maior rebanho bovino do mundo: em 2016 o efetivo ultrapassou 2 I8,23 milhões de cabeças (IBGE, 2OI7). ${ }^{3}$ A Índia é o país que figura em primeiro lugar no ranking mundial, sendo importante considerar, entretanto, que nesse país as reses não são abatidas por motivos religiosos, o que coloca o Brasil como o detentor do maior rebanho bovino comercial do mundo. Anualmente são abatidas no Brasil cerca de 30 milhões ${ }^{4}$ de cabeças de gado. Trata-se de uma cadeia produtiva que movimentou em 2015 um valor estimado em $\mathrm{R} \$ 483,5$ bilhões (ABIEC, 20I6), e as projeções foram otimistas para o setor: o Ministério da Agricultura estimou que até 2025 as exportações de carne bovina cresçam em 37,4\% (BRASIL, 20I5). Conforme dados da Associação Brasileira das Indústrias Exportadoras de Carnes (ABIEC, 20I6), o mercado interno permanece com a maior fatia da carne bovina produzida no país (8I,38\%), e o consumo per capita dos brasileiros é estimado em $38,6 \mathrm{~kg} /$ ano.

A bovinocultura de corte também ocupa uma grande extensão do território brasileiro, aproximadamente 167 milhões de hectares de terra (ABIEC, 20I6). A região Centro-Oeste registra, nos dias de hoje, os maiores índices de crescimento do rebanho bovino, ao passo que regiões historicamente identificadas com a pecuária, como as regiões Sul e Nordeste, têm visto seu rebanho permanecer estável ou mesmo diminuir. ${ }^{5}$ Não apenas a distribuição geográfica das fazendas de gado de corte pelo território nacional tem sido transformada, mas também o sistema produtivo vem se alterando profundamente com a disseminação dos confinamentos de gado de corte, a introdução de suplementos minerais e de rações na dieta dos bovinos e a grande expansão dos métodos de inseminação artificial.

Os confinamentos de gado de corte, que correspondem ao sistema norte-americano Concentrated Animal Feeding Operation (CAFOs, Operação Intensiva de Alimentação Animal, em tradução livre), adquirem expressividade no Brasil a partir dos anos I980 (MOREIRA et al., 2009). Nesse sistema, "os animais são colocados em piquetes ou currais de engorda com área que restringe a locomoção dos mesmos, e onde os alimentos são fornecidos de forma controlada nos cochos" (MOREIRA et al., 2009, p. I33). No Brasil, o gado é confinado apenas na fase final de engorda por cerca de três meses. Por seu turno, no sistema norte-americano o rebanho pode ser confinado desde o nascimento até o abate.

O crescimento numérico da pecuária teve participação decisiva do Estado brasileiro que, desde os anos I970, no período da ditadura militar, investiu pesadamente no agronegócio da carne

\footnotetext{
${ }^{3}$ A título de comparação, em 1970, o efetivo do rebanho bovino alcançava cerca de 78,6 milhões de cabeças de gado (LEMOS, 2013).

${ }^{4}$ O recorde nacional data de 2013, quando foram abatidas 34,41 milhões de cabeças de gado (IBGE, 2016). Esse número sofreu uma queda em 2015, quando o total de abates alcançou os 30,65 milhões (IBGE, 2016).

${ }^{5}$ Em 2015, o rebanho bovino da região Nordeste sofreu redução de 0,9\%, e na região Sul esse índice se manteve estável. Mato Grosso é o estado com o maior rebanho bovino, 28.457 .770 de cabeças, correspondendo a 13,6\% do efetivo brasileiro (ABIEC, 2016). Em estados como São Paulo, Paraná e Rio Grande do Sul, a bovinocultura tem cedido espaço aos plantios de soja, cana-de-açúcar e milho (SCHLESINGER, 2010).
} 
através de programas de incentivo e isenções fiscais, bem como por meio de um pacote tecnológico fundado no uso de agrotóxicos, fertilizantes, máquinas e aprimoramento genético (LEAL, 2OI4; LEMOS, 2OI3; MEDRADO, 2OI3).

O entusiasmo dos números do agronegócio da carne, no entanto, tem sido contrabalançado pelo recrudescimento das críticas dirigidas à industrialização da pecuária e aos métodos empregados na produção de carne. O estabelecimento de uma "agenda anticarnívora" ganha força na atuação de organizações não governamentais e entidades da sociedade civil que têm denunciado, ${ }^{6}$ dentre outros, o papel decisivo da pecuária no desmatamento do Cerrado e da Amazônia; no aquecimento global e na crise climática; na manutenção de trabalhadores em regimes análogos à escravidão; e também o emprego de técnicas violentas e cruéis de manejo dos animais.

A recente publicação Cadeia industrial da carne (AGUIAR; TURA, 20I6) apresenta as consequências e os impactos da crescente concentração do complexo industrial global da carne. Nos Estados Unidos, por exemplo, quatro empresas controlam a produção: Tyson, Cargill, National Beef e JBS. Esta última, brasileira, é hoje a maior processadora mundial de carnes, crescimento que teve amplo apoio de instituições públicas brasileiras como o Banco Nacional de Desenvolvimento Econômico e Social(BNDES) e a Caixa Econômica Federal. ${ }^{7}$ Segundo os autores, tal concentração e tecnificação subjacente à industrialização da produção de carne implicam transformações profundas não apenas na atividade produtiva em si, mas avançam em suas consequências sobre os modos de vida de povos e comunidades tradicionais - cujos territórios vêm sendo subtraídos em nome da ampliação da fronteira agrícola -, fontes de água limpa e biodiversidade, além de impactar definitivamente na soberania dos povos e na segurança alimentar.

Quanto às condições de trabalho, a pecuária é caracterizada por grande informalidade e recorrentes acusações de manutenção de trabalhadores sob regimes de escravidão (SCHLESINGER, 20IO; HEINRICH BÖLL FOUNDATION, 20I6). A indústria de abate, por sua vez, está entre as que mais comporta riscos aos trabalhadores: exposição a objetos cortantes; realização de movimentos repetitivos causadores de lesões, por vezes permanentes; pressão psicológica em função do ritmo de trabalho e de jornadas exaustivas em ambientes extremamente frios são alguns desses riscos (REPÓRTER BRASIL, 2OI3).

\footnotetext{
${ }^{6}$ Por meio de publicações tais como Conexões sustentáveis, produzida pelas ONGs Repórter Brasil e Papel Social (SAKAMOTO; CASARA, 2008); e $O$ reino do gado, das ONGs Amigos da Terra e Amazônia Brasileira (SMERALDI; MAY, 2008); a publicação on-line A farra do boi na Amazônia, do Greenpeace (2009); o estudo Onde pastar?, publicado pela ONG Fase (SCHLESINGER, 2010); o livreto Moendo gente, pela Repórter Brasil (2013); as publicações Atlas da carne, da Heinrich Böll Foundation (2016), e Cadeia industrial da carne, da Fase (AGUIAR; TURA, 2016).
}

${ }^{7}$ Por meio do BNDES Participações, o banco detém 24,58\% das ações da JBS, e da Caixa Econômica Federal, outros 10,8\% (SCHLESINGER, 2016). 
As condições de vida dos animais nas fazendas industriais também vêm se alterando radicalmente e, desde pelo menos a década de 1960 , diversas obras têm sido publicadas no intuito de questionar o uso dos animais para fins alimentares. Ao relato pioneiro de Ruth Harrison em Animal machines (1964), somam-se obras como Libertação animal, de Peter Singer [1975](2004), e a mais recente, Jaulas vazias (2006), de Tom Regan, as quais inspiram movimentos em prol do vegetarianismo $^{8}$ e do veganismo ao redor do mundo. Para além da crítica ao uso humano dos animais em si, tais obras descrevem em detalhes os efeitos da industrialização da criação animal. A alta densidade dos sistemas de confinamento industriais, as dietas excessivamente calóricas, o uso indiscriminado de hormônios de crescimento e antibióticos, a utilização de métodos violentos no manejo dos animais nas propriedades rurais e as condições de abate nos frigoríficos são alguns dos temas a mobilizar ativistas em prol dos direitos dos animais.

Os danos ambientais causados pela indústria da carne são tema recorrente no universo vegetariano e vegano, ainda que sua abordagem difira daquela evocada por movimentos ambientalistas. ${ }^{9}$ A atividade pecuária é apontada como a maior causa de desmatamento no Brasil, e as pressões pelo uso racional do espaço coadunam-se às exigências internacionais em prol de medidas efetivas de bem-estar animal. A poluição do ar e da água, a perda ou redução da biodiversidade, a erosão, o desmatamento, a emissão de gases de efeito estufa são algumas das consequências associadas à pecuária, as quais perpassam toda a cadeia produtiva, desde as fazendas até os supermercados.

A Sociedade Vegetariana Brasileira (SVB) sistematizou informações sobre a questão ambiental ligada ao consumo de alimentos de origem animal em uma publicação de 24 páginas intitulada Impactos sobre o meio ambiente do uso de animais para alimentação (2OI-). Segundo a publicação, no Brasil, um quilo de carne bovina é responsável, em média, pelo desmatamento de Io mil metros quadrados de floresta, e sua produção gasta em torno de 15 mil litros de água doce limpa. Além do desmatamento e do desperdício de água, o despejo de metais pesados provenientes de fertilizantes e defensivos agrícolas no solo e a contaminação dos lençóis freáticos por esses metais e também por antibióticos, hormônios e vacinas - liberados no solo pela urina e pelas fezes dos animais - são outros agentes que entram no cálculo dos custos ambientais oriundos da pecuária (SOCIEDADE VEGETARIANA BRASILEIRA, [2OI-]).

Por sua vez, no seio de organismos multilaterais como a Organização das Nações Unidas para a Agricultura e a Alimentação (FAO), a produção e o consumo de carne também são matéria de controvérsias e de disputas. Em que pese o reconhecimento do papel da pecuária no agravamento

\footnotetext{
${ }^{8}$ Em linhas gerais, o vegetarianismo é um regime alimentar que exclui todos os tipos de carnes. O veganismo ou vegetarianismo estrito, por sua vez, exclui quaisquer produtos de origem animal (incluindo leite e ovos), não apenas na dieta, mas nas formas de couro, medicamentos e cosméticos testados em animais.

${ }^{9}$ Os interlocutores ligados ao abolicionismo animal na pesquisa de Sordi (2011) afirmam existir um conflito de prioridades em relação aos movimentos ambientalistas. Estes, para os abolicionistas, centrariam suas forças em entidades abstratas, como "ambiente" e "ecossistema", relegando o animal e seu sofrimento para um segundo plano, ou mesmo não abordando a questão.
} 
da crise climática e ambiental, a introdução de uma dieta à base de carne nos países em desenvolvimento é vista, por outro lado, como estratégia de combate à fome e à desnutrição. A articulação dos enunciados "preservação ambiental" e "produção/consumo de carne" resulta em sentenças múltiplas e diversas, envolvendo a pecuária e o consumo de carne em questões de crescente complexidade.

No relatório Livestock's long shadow: environmental issues and options, produzido pela Livestock, Environment and Development Initiative, da FAO, a agricultura animal é apontada como a causa da emissão de I8\% da totalidade dos gases de efeito estufa, sendo a atividade responsável pela ocupação da maior quantidade de terras no mundo (FAO, 2006). O relatório destaca também o papel dos cultivos da soja e do milho na destruição das florestas, salientando que a maior parte dessa produção é utilizada na alimentação animal (60\% do milho e $97 \%$ do farelo de soja) (FAO, 2006).

Mais recentemente, em 20I6, foi elaborado no âmbito do Painel de Alto Nível de Especialistas em Segurança Alimentar e Nutricional, vinculado ao Comitê de Segurança Alimentar Mundial, ${ }^{10}$ o relatório Sustainable agricultural development for food security and nutrition: what roles for livestock?. O relatório reconhece o papel central desempenhado pela cadeia da carne no desenvolvimento do setor agrícola na contemporaneidade e busca identificar os impactos, tanto negativos como positivos, da produção e do consumo de carnes na perspectiva do desenvolvimento sustentável e da garantia da segurança alimentar e nutricional. Identifica ainda a existência de diferentes sistemas de produção animal, com trajetórias particulares de desenvolvimento e desafios específicos no que diz respeito à readequação em uma perspectiva de sustentabilidade.

\section{Bois sustentáveis}

Atentos às discussões elencadas, os agentes do agronegócio têm buscado reverter a imagem negativa da pecuária descrita em termos de exploração do trabalho humano, da crueldade com os animais e da devastação do ambiente (LEWGOY; SORDI, 20I2). Tais acusações são recusadas pela indústria da carne e ressignificadas em expressões tais como "responsabilidade social", "bemestar animal" e "sustentabilidade ambiental", elementos que configuram o tripé no qual se assenta a oferta de alimentos "éticos", a ser garantida ao consumidor por meio de selos e certificações de origem e qualidade. Ademais, as ações de marketing e as campanhas publicitárias da indústria da carne têm enfatizado a importância da carne como fonte de proteínas e a base de uma dieta saudável e nutritiva.

Durante a pesquisa de campo do doutorado (FROEHLICH, 20I6), em conversas com pecuaristas, zootecnistas e médicos veterinários; em congressos e palestras com representantes

\footnotetext{
${ }^{10}$ Em inglês, High Level Panel of Experts on Food Security and Nutrition, vinculado ao Committee on World Food Security (CFS). O CFS está estruturado como um comitê intergovernamental no âmbito da FAO e como uma plataforma de discussão e coordenação de ações cujo objetivo é eliminar a fome e garantir a segurança alimentar e nutricional em nível global, mobilizando, além dos governos, um amplo conjunto de atores. Disponível em: <http://www.fao.org/cfs/cfs-hlpe/en/>. Acesso em: 10 abr. 2018.
} 
de institutos de pesquisa e órgãos de certificação; bem como no acompanhamento dos debates entre os agentes da rede produtiva da carne em seus portais na internet, pude perceber uma preocupação crescente com a assim chamada "questão ambiental" e em relação às críticas que vêm sendo dirigidas à pecuária por sua contribuição na crise climática e no aquecimento global. Conversei com pecuaristas, agrônomos e veterinários que afirmam de maneira contundente que os argumentos dos movimentos ambientalistas figuram, atualmente, como a principal fonte de pressão no que diz respeito à transformação das práticas agropecuárias e como uma importante ameaça à atividade econômica desenvolvida pelo setor.

A campanha Carne ao Molho Madeira, ${ }^{11}$ lançada pelo Greenpeace, em 2015, foi mencionada nessas conversas. A ação teve como objetivo pressionar supermercados, os maiores compradores de carne, a adotar medidas capazes de garantir que a carne comercializada por esses estabelecimentos não seja proveniente de rebanhos de gado criados em áreas de desmatamento na Amazônia. A campanha toma como base um estudo realizado nas sete principais redes varejistas que atuam no Brasil (Walmart, Carrefour, Grupo Pão de Açúcar, Cencosud, Pereira Comper, Grupo DB e Yamada) e que concentram dois terços do varejo nacional. Para o Greenpeace, nenhum dos supermercados analisados alcançou o patamar "verde", ou seja, nenhuma das redes supracitadas consegue garantir que I00\% da carne comercializada é livre de crimes socioambientais. No lançamento da campanha, ativistas dirigiram-se a uma unidade do Pão de Açúcar e afixaram adesivos nas embalagens de carne, além de distribuir panfletos com os resultados da pesquisa que embasou a ação. "Você sabe de onde vem a carne que está no seu prato?", "O que tem na carne?" e "Desmatamento não dá pra engolir!", são algumas das frases de chamada da campanha, que centraliza sua intervenção no poder do consumidor visando pressionar as redes de varejo.

Órgãos do Estado, a exemplo do Banco Nacional de Desenvolvimento Econômico e Social (BNDES) com a publicação de "Panorama da pecuária sustentável" (AMARAL et al., 20I2), reconhecem que a pecuária bovina se constitui como um dos maiores agentes de desmatamento, emissão de gases de efeito estufa, degradação do solo, poluição dos rios e mananciais e diminuição da biodiversidade. A bovinocultura de corte foi responsável, por exemplo, por $85 \%$ da emissão de metano em 2005 (AMARAL et al., 20I2). Ainda sobre o metano, a criação de animais em confinamento, em função de seus dejetos, forma açudes de dimensões variadas que constituem a principal fonte de emissão desse gás. Por outro lado, a pecuária extensiva emite menos metano em função da não concentração desses dejetos, ainda que promova maior desmatamento, uma vez que a área necessária para esse modelo de criação é superior à área dos confinamentos.

$\mathrm{O}$ artigo mencionado constata também a recente expansão da fronteira agropecuária para o bioma amazônico, sendo que os estados do Pará e de Rondônia têm registrado os maiores índices

\footnotetext{
${ }^{11}$ Disponível em: <http://carneaomolhomadeira.org.br/>. Acesso em: 12 abr. 2018.
} 
de crescimento do rebanho bovino no Brasil. Embora os autores reconheçam o papel da pecuária na crise climática e ambiental, afirmam que "a tendência é de crescente sustentabilidade socioambiental da pecuária" (Amaral et al., 2012, p. 250), como exemplificado através de iniciativas como o Programa Agricultura de Baixo Carbono (Programa ABC), que visa reduzir a emissão de gases de efeito estufa por meio de recursos e incentivos às propriedades que implantam técnicas agrícolas sustentáveis.

A incorporação da crítica ambientalista pelas empresas e sua versão em medidas efetivas voltadas à reorganização da atividade produtiva, à implantação de sistemas de certificação orientados por princípios de sustentabilidade e, como desdobramento, em ações de marketing, se apresentam como uma fonte de legitimidade junto ao mercado e à sociedade. Essas dinâmicas de crítica e de contestação que atravessam a organização do processo de trabalho, os mercados e as relações com a natureza constituem-se como uma nova roupagem das complexas dinâmicas de ambientalização dos conflitos sociais (LEITE LOPES, 2006).

No sentido proposto por Leite Lopes (2006), a "ambientalização" dos conflitos sociais diz respeito "ao processo histórico de construção de novos fenômenos, associado a um processo de interiorização pelas pessoas e pelos grupos sociais [...] das diferentes facetas da questão pública do "meio ambiente'" (p. 34). É preciso reter dessa definição sua perspectiva processual; a ambientalização transforma o Estado e também o comportamento das pessoas, suas atividades de lazer, de consumo e de trabalho (LEITE LOPES, 2006). Transforma também as práticas empresariais ao agregar lucratividade material e simbólica aos discursos e às práticas "ambientalmente corretas".

Os selos Carne Carbono Neutro e Pecuária Neutra em Metano Entérico figuram como duas iniciativas brasileiras de certificação em sustentabilidade ilustrativas dos expedientes de ambientalização da cadeia produtiva da carne. O projeto "Carne Carbono Neutro" foi desenvolvido pela Embrapa e visa atestar que a carne bovina foi produzida mediante processos de neutralização dos gases de efeito estufa (GEE) em empreendimentos de integração pecuáriafloresta (silvipastoril) ou pecuária-lavoura-floresta (agrossilvipastoril) (ALVES et al., 2015). A integração entre pecuária e floresta é também a base do projeto Pecuária Neutra em Metano Entérico, desenvolvido pela ação de três pecuaristas de Minas Gerais. O plantio de árvores, especialmente o eucalipto, nesses sistemas de integração proporciona, por um lado, a neutralização dos GEEs, demonstrada através de complexos cálculos de retenção (com diferentes resultados de neutralização para caules, raízes e copas); e, por outro, constitui uma fonte de altos rendimentos por meio da venda da madeira e da carne certificada. Além da comercialização de carne e de madeira certificadas, os projetos preveem a geração de créditos de carbono como estratégia para a expansão futura dos empreendimentos. 
O selo Rainforest Alliance Certified $\left(\mathrm{RAC}^{\mathrm{TM}}\right)$ para carnes ${ }^{12}$ concedido no Brasil pelo Instituto de Manejo e Certificação Agrícola (Imaflora) está no mercado desde 20I2. A Rainforest Alliance é uma organização internacional sem fins lucrativos, com sede nos Estados Unidos, formada por agricultores, governantes, ambientalistas e empresas que tem por objetivo a conservação da biodiversidade por meio de práticas sustentáveis. ${ }^{13} \mathrm{O}$ selo $\mathrm{RAC}^{\mathrm{TM}}$ "diferencia as propriedades rurais que adotam boas práticas sociais, ambientais e de produção agropecuária em suas atividades. Entre elas, estão a conservação dos recursos naturais e ecossistemas, a contribuição para o bem-estar da comunidade e o respeito ao trabalhador" (IMAFLORA, 2015, p. 20).

A adesão aos protocolos é voluntária e as certificações são conferidas às propriedades rurais em função dos métodos empregados no processo produtivo. As fazendas que desejarem habilitarse pelo programa devem solicitar auditorias que avaliam a adequação dos empreendimentos às exigências do protocolo. Aos produtores rurais a certificação é promovida como um mecanismo para aprimorar o gerenciamento das propriedades por meio do controle dos índices de produtividade e como uma ferramenta de diferenciação dos seus produtos no mercado. Um dos princípios da certificação Rainforest Alliance é o desenvolvimento e o aprimoramento das práticas de gestão administrativa, de maneira a reduzir o desperdício e aumentar a eficiência no uso dos recursos. Conforme relatado na publicação A busca pela sustentabilidade no campo: Io anos de certificação agrícola no país (IMAFLORA, 2012), as maiores transformações proporcionadas pela certificação "estão na melhor gestão do empreendimento e no pleno conhecimento da propriedade e dos sistemas de produção, de organização e de planejamento" (p. I23).

Em conversas com representantes da certificadora Imaflora durante a pesquisa de campo do doutorado, eles enfatizaram que o mercado consumidor de carnes certificadas, apesar de ainda restrito, encontra-se em expansão. Eduardo Trevisan, gerente de projetos do Imaflora, em entrevista concedida ao site de notícias da rede BeefPoint sobre a certificação agrícola, afirma que "a aceitação dos consumidores é muito boa, hoje falta carne certificada no mercado. A demanda de consumidores principalmente da Europa é muito alta, e o Brasil atualmente não tem conseguido atender a procura" (TREVISAN, 20I3). ${ }^{14}$

O esforço que vem sendo feito por parte da certificadora em parceria com os frigoríficos e os pecuaristas está em associar o selo Rainforest a marcas de carne e assim produzir reconhecimento para as fazendas e para os frigoríficos, uma vez que ambos precisam ser certificados para que o produto receba o selo. Segundo Trevisan (2013), o trabalho de divulgação da certificação dos

\footnotetext{
${ }^{12}$ A trajetória de certificação Rainforest iniciou-se com produtos como o café, a laranja e o cacau. No Brasil, a primeira cultura com o selo Rainforest certificada pelo Imaflora foi o café, em 2003.

${ }^{13}$ Descrição disponível em: <https://www.rainforest-alliance.org/about>. Acesso em: 10 abr. 2018. Observa-se que a instituição apresentase como "sem fins lucrativos", embora promova a certificação para os empreendimentos tanto como forma de difusão de práticas de sustentabilidade quanto como um mecanismo de diferenciação dos produtos e, assim, incremento nos lucros.
}

${ }^{14}$ A entrevista completa está disponível em: <http://www.beefpoint.com.br/eduardo-trevisan-aceitacao-dos-consumidores-e-muito-boaporem-falta-carne-certificada-no-mercado/>. Acesso em: 3 abr. 2018. 
produtos tem se concentrado nos frigoríficos e nas associações de criadores de gado de corte. No atual estágio de difusão das práticas de sustentabilidade, quando a certificadora pensa em consumidores ela está se referindo não ao consumidor final, aquele que compra a carne no supermercado, mas aos próprios supermercados, restaurantes, redes de fast food e fabricantes de artigos de couro que desejam oferecer uma linha de produtos caracterizados como sustentáveis. O gerente de Sustentabilidade da Marfrig Beef, Mathias Almeida, em reportagem da página institucional da empresa que destacava a produção de hambúrgueres com o selo Rainforest, afirmou que "a principal diferença entre os produtos produzidos com a carne certificada e os demais não é percebida nas gôndolas, por isso ainda há um grande trabalho de divulgação a ser feito junto ao consumidor" (TREVISAN, 20I3). ${ }^{15}$

Esse deslocamento discursivo operado na definição da crise ambiental, que transfere para a esfera do consumo os problemas e os impactos ambientais gerados pelo processo produtivo, é problematizado por Portilho (2005). A autora demonstra que as consequências desse deslocamento são ambivalentes. Se por um lado esse processo pode significar o fortalecimento da autoridade dos consumidores e o sentimento de pertencimento na sociedade - possibilitado pela troca de experiências entre os indivíduos -, a ênfase no poder do consumidor pode implicar um maior controle da vida cotidiana (pela transformação das exigências ambientais em imperativos morais), bem como dificultar a coletivização dos problemas ambientais por individualizar em demasia esses problemas e sua solução.

Dessa maneira, a ambientalização da cadeia produtiva da carne via selos de sustentabilidade envolve também a ambientalização das práticas de consumo. A estratégia do consumo verde exemplificado neste texto pelas certificações Carne Neutra, Carne Carbono Neutro e RAC ${ }^{\mathrm{TM}}$ operaria, assim, uma dupla transferência da atividade regulatória

do Estado para o mercado, através de mecanismos de auto-regulação; e do Estado e do mercado para o cidadão, através de suas escolhas de consumo. Assim, ambos - governos e empresas - encorajariam a responsabilidade individual, implícita ou explicitamente, através de referências ao poder do consumidor, ao "bom cidadão" ou à valorização da contribuição pessoal de cada um, transferindo a responsabilidade para um único lado da equação: o indivíduo. (PORTILHO, 2005, p. 3).

Para os produtores, por sua vez, a sustentabilidade é transformada em um nicho de mercado: deixa de ser um empecilho à lucratividade para converter-se em um de seus agentes potenciais. A operação de conversão é semelhante àquela efetuada com a categoria de "bem-estar animal", incorporado no conceito geral de sustentabilidade. Estudos desenvolvidos na área de administração e consumo questionam se "respeitar os animais pode ser um bom negócio" (SOUZA et al., 20I3, p. 229). Souza et al. (2013) asseveram que quando os consumidores são expostos às

\footnotetext{
${ }^{15}$ Disponível em: <http://www.marfrig.com.br/pt/documentos?id=734>. Acesso em: 8 abr. 2018.
} 
práticas industriais de produção de carne pode haver "redução de consumo e migração para substitutos" (p. 242). Para as empresas, no entanto, "esses achados podem ser vistos como uma oportunidade de antecipação a uma nova consciência crítica, trazida à tona pela economia da informação ou mesmo como uma oportunidade de atender aos anseios de grupos de consumidores mais preocupados com a ética e com a sustentabilidade" (p. 242).

Por seu turno, a incorporação de discursos e práticas que tematizam o ambiente em produtos pelas empresas e pelo Estado nos remete à "intrusão de Gaia" sobre a qual nos falam os estudos do Antropoceno. Gaia, no sentido atribuído por Stengers (2015) a partir das obras de James Lovelock e Lynn Margulis, nos anos I970, evoca um "agenciamento de relações" que tem uma história e um regime próprio de atividades; não é sinônimo de uma natureza "selvagem e ameaçadora" ou de uma natureza frágil, tampouco passível de exploração irrestrita (STENGERS, 2015, p. 38-39). A intrusão de Gaia coloca um desafio às alternativas de proteção ou exploração e, consequentemente, à proposta reformista de sustentabilidade engendrada por megacorporações e embutida em certificações socioambientais. A reapropriação lucrativa da problemática ambiental por empresas e empreendimentos acusados pública e notoriamente de degradação ambiental vai ao encontro do que afirma Stengers (2015):

Como já se compreendeu, confiar no capitalismo que se apresenta hoje como o "melhor amigo da Terra", como "verde", preocupado com a preservação e com a durabilidade, seria cometer o mesmo erro que o sapo da fábula, que aceita carregar um escorpião em suas costas para que ele atravesse um rio. "Se ele o aferroasse, não se afogariam os dois?", o escorpião argumenta. Ele o aferroa, no entanto, e bem no meio das águas. Em seu último suspiro o sapo pergunta: "Por quê?" A que o escorpião, prestes a afundar, responde: "é da minha natureza, não posso evitar". É da natureza do capitalismo explorar as oportunidades, ele não pode evitar. (p. 47).

Na perspectiva adotada pelas certificações, tanto a natureza quanto os animais são abordados como recursos. Nesse sentido, tornam-se artigos de gerenciamento que podem ser melhor administrados e cuja produtividade pode ser incrementada com práticas sustentáveis e de bemestar, mas não a despeito delas. Retomando a narrativa de Okja, o desenvolvimento de "superanimais" - altamente produtivos, de baixo impacto ambiental, rápido crescimento e carne saborosa - alinha-se às estratégias do capitalismo verde que explora a oportunidade colocada pela crise climática e ambiental porque, afinal, como assevera Stengers (20I5), é da natureza do sistema aproveitar-se das oportunidades.

\section{Referências}

ABIEC. Perfil da pecuária no Brasil. Relatório Anual. 2016. Disponível em:

$<$ http://abiec.siteoficial.ws/images/upload/sumario-pt-oIO2 I7.pdf >. Acesso em: I2 abr. 2018. ACSELRAD, H. Ambientalização das lutas sociais - o caso do movimento por justiça ambiental.

Estudos Avançados, v. 24, n. 68, p. IO3-II9, 2010. 
AGUIAR, D.; TURA, L. Cadeia industrial da carne. Compartilhando ideias e estratégias sobre o enfrentamento do complexo industrial global de alimentos. Rio de Janeiro: Fase, 2016.

ALVES, F.; ALMEIDA, R. G. de; LAURA, V. A. Carne Carbono Neutro: um novo conceito para carne sustentável produzida nos trópicos. Campo Grande, MS: Embrapa Gado de Corte, 2015.

AMARAL, G.; CARVALHO, F.; CAPANEMA, L.; CARVALHO, B. A. de. Panorama da pecuária sustentável. Brasília: BNDES Setorial 36, 2012. p. 249, 288.

ATWOOD, M. Oryx e Crake. Rio de Janeiro: Rocco, 2004.

BRASIL. Ministério da Agricultura, Pecuária e Abastecimento. [MAPA]. Projeções do agronegócio. Brasil 2OI4/15 a 2O24/25. Projeções de longo prazo. Brasília, DF: Assessoria de Gestão Estratégica, 2015.

CRUTZEN, P. J. Geology of mankind. Nature, v. 415, n. 23, 2002.

CRUTZEN, P. J.; STOERMER, E. F. The Anthropocene. IGBP [International Geosphere-Biosphere Programme] Newsletter, n. 4I, 2000.

FAO. Livestock's long shadow: environmental issues and options. Food and Agriculture Organization of the United Nations. Roma. 2006. Disponível em: $<$ http://www.fao.org/docrep/oIo/ao7ore/ao7oreoo.HTM>. Acesso em: I5 abr. 2018.

FAOSTAT. Livestock primary data. 2013. Disponível em: <http://faostat3.fao.org >. Acesso em: I5 abr. 2018.

FROEHLICH, G. O bem-estar na carne. Um estudo antropológico das relações entre humanos e animais a partir da categoria de bem-estar animal. 283f. Tese (Doutorado em Antropologia Social) - Instituto de Ciências Sociais, Universidade de Brasília, Brasília, 2016.

GREENPEACE. A farra do boi na Amazônia. São Paulo; Manaus: Greenpeace, 2009.

HARRISON, R. Animal machines. London, UK: Vincent Stuart Ltd, I964.

HEINRICH BÖLL FOUNDATION. Atlas da carne: fatos e números sobre os animais que comemos. Rio de Janeiro: Heinrich Böll Foundation, 2016.

IBGE. Estatística da produção pecuária. Indicadores IBGE. Rio de Janeiro: IBGE, 2OI6. Disponível em: $<$ https://biblioteca.ibge.gov.br/visualizacao/periodicos/2380/epp_20I6_mar.pdf $>$. Acesso em: 15 abr. 2018.

IBGE. Produção da pecuária municipal 2016. V.44. 20I7. Disponível em: $<$ https://biblioteca.ibge.gov.br/visualizacao/periodicos/84/ppm_20I6_v44_br.pdf $>$. Rio de Janeiro: IBGE, 2OI7. Acesso em: I2 abr. 2018.

IMAFLORA. A busca pela sustentabilidade no campo: Io anos de certificação agrícola no Brasil. Piracicaba, SP: Imaflora, 2012.

IMAFLORA. Relatório anual 20I4. 2015. Disponível em: $<$ http://www.imaflora.org/downloads/biblioteca/56004Iffod39d_relatorio_2015.pdf $>$. Acesso em: 15 out. 2019. 
LEAL, N. Nome aos bois. Zebus e zebuzeiros em uma pecuária brasileira de elite. 320f. Tese (Doutorado em Antropologia Social) - Faculdade de Filosofia, Letras e Ciências Humanas, Universidade de São Paulo, São Paulo, 2014.

LEITE LOPES, J. S. Sobre processos de "ambientalização" dos conflitos e sobre dilemas da participação. Horizontes Antropológicos, ano I2, n. 25, p. 31-64, 2006.

LEMOS, F. K. A evolução da bovinocultura de corte brasileira: elementos para a caracterização do papel da ciência e da tecnologia na sua trajetória de desenvolvimento. 239f. Dissertação (Mestrado em Engenharia de Produção) - Escola Politécnica da Universidade de São Paulo, São Paulo, 2013.

LEWGOY, B.; SORDI, C. As guerras da carne: o consumo carnívoro, seus defensores e críticos: novas e velhas configurações. In: STEIL, C. A.; CARVALHO, I. (Org.). Cultura, percepçãoe ambiente: diálogos com Tim Ingold. São Paulo: Terceiro Nome, 2012. p. I37-I5I.

MEDRADO, J. Do pastoreio à pecuária. A invenção da modernização rural nos sertões do Brasil Central. 255f. Tese (Doutorado em História) - Universidade Federal Fluminense, Niterói, 2013.

MOREIRA, S. A.; THOMÉ, K. M.; FERREIRA, P. da S.; BOTELHO FILHO, F. B. Análise econômica da terminação de gado de corte em confinamento dentro da dinâmica de uma propriedade agrícola.Custose@gronegócio online, v. 5, n. 3, p.132-152, 2009.

OKJA. Direção Bong Joon-ho. EUA; Coreia do Sul: Netflix, 20I7. II8 minutos.

PORTILHO, F. Consumo sustentável: limites e possibilidades de ambientalização e politização das práticas de consumo. Cadernos EBAPE.BR (FGV), v. III, p. I-I2, 2005.

REGAN, T. Jaulas vazias: encarando o desafio dos direitos animais. Porto Alegre: Lugano, 2006.

REPÓRTER BRASIL. Moendo gente: a situação do trabalho nos frigoríficos. São Paulo: ONG Repórter Brasil, 2013.

ROCKSTRÖM, J.; STEFFEN, W.; NOONE, K.; PERSSON, A. et al. A safe operating space for humanity. Nature, v. 46I, p. 472-475, 2009.

SAKAMOTO, L.; CASARA, M. Conexões sustentáveis: São Paulo - Amazônia. Quem se beneficia com a destruição da Amazônia. São Paulo: ONG Repórter Brasil; Papel Social Comunicação, 2008.

SCHLESINGER, S. A cadeia produtiva de carnes no Brasil. In: AGUIAR, D.; TURA,

L. Compartilhando ideias e estratégias sobre o enfrentamento do complexo industrial global de alimentos. Rio de Janeiro: Fase, 2016.

SCHLESINGER, S. Onde pastar? O gado bovino no Brasil. Rio de Janeiro: Fase, 2010.

SINGER, P. Libertação animal. Porto Alegre: Lugano, 2004 [1975].

SMERALDI, R.; MAY, P. H. O reino do gado: uma nova fase na pecuarização brasileira. São Paulo: Amigos da Terra - Amazônia Brasileira, 2008. 
SOCIEDADE VEGETARIANA BRASILEIRA. Impactos sobre o meio ambiente do uso de animais para alimentação. São Paulo: [2OI-].

SORDI, C. O animal como próximo. Caderno IHU Ideias. São Leopoldo: Unisinos, 201 I.

SOUZA, M. C. G.; CASOTTI, L. M.; LEMME, C. F. Consumo consciente como determinante da sustentabilidade ambiental: respeitar os animais pode ser um bom negócio? Rev. Adm. UFSM, Santa Maria, v. 6, Edição Especial, p. 229-246, 2013.

STENGERS, I. No tempo das catástrofes. São Paulo: Cosac Naify, 2015.

TREVISAN, E. Eduardo Trevisan: aceitação dos consumidores é muito boa, porém, falta carne certificada no mercado. Entrevista concedida ao site BeefPoint. 20I3. Não paginado.

Disponível em: <http://www.beefpoint.com.br/eduardo-trevisan-aceitacao-dosconsumidores-e-muito-boa-porem-falta-carne-certificada-no-mercado/>. Acesso em: I2 abr. 2018. 